\title{
BIONANOPARTÍCULAS: PRINCIPAIS ASPECTOS E APLICAÇÕES DA MATÉRIA ORGÂNICA EM ESCALA NANOMÉTRICA
}

\author{
A. M. N. TOLEDO e L. A. S. SOARES \\ Universidade Federal do Rio Grande (FURG)/RS \\ matiasnavarrete@yahoo.com.br*
}

Artigo submetido em junho/2014 e aceito em julho/2015

DOI: $10.15628 /$ holos.2016.2209

\section{RESUMO}

A nanotecnologia é o termo utilizado para descrever a criação, manipulação e exploração de materiais em escala nanométrica. Bionanotecnologia é a aplicação da nanotecnologia nas ciências da vida, onde a matéria prima para obtenção de nanopartículas é de origem biológica. Esta ciência tem despertado grande interesse por ser de fontes renováveis, pela possibilidade de obtenção de novas propriedades dos materiais, que em dimensão nano, são totalmente modificadas, pela maior possibilidade de biocompatibilidade com o organismo humano, pelo auxílio em tratamentos mais eficazes de doenças (liberação controlada de fármacos), bem como no diagnóstico preventivo na área da saúde (agentes de imagem) e no controle de qualidade dos produtos da agroindústria (biossensores). O objetivo des ta revisão foi abordar as bionanopartículas de maior evidência no campo da nanotecnologia, enfatizando as nanopartículas de quitosana, nanofibras de celulose e recentes estudos com Spirulina platensis, focando em seus processos de obtenção, suas características em escala nanométrica e suas aplicações nos diversos campos da ciência e tecnologia.

PALAVRAS-CHAVE: Bionanotecnologia, quitosana, Spirulina, celulose.

\section{BIONANOPARTICLES: THE MAIN ISSUES AND APPLICATIONS OF ORGANIC MATTER IN NANOSCALE}

\begin{abstract}
Nanotechnology is the term used to describe the creation, manipulation and exploitation of materials at the nanometer scale. Bionanotechnology is the application of nanotechnology in the life sciences, where the raw material for the production of nanoparticles is of biological origin. This science has attracted great interest as renewable sources, the possibility of obtaining new properties of materials at the nano scale that are fully modified, the greater possibility of biocompatibility with the human body, by the aid in more effective treatments
\end{abstract}

of diseases (controlled release of drugs) and preventive diagnostics in health (imaging agents) and quality control of agro-industry bioproducts. The objective of this review was to address the bionanoparticles greater evidence in the field of nanotechnology, emphasizing the chitosan nanoparticles, nanofibers of cellulose and Spirulina platensis with recent studies, focusing on its procedures its characteristics on the nanometer scale and its applications in diverse fields science and technology.

KEYWORDS: Bionanotechnology, Chitosan, Spirulina, Cellulose. 


\section{INTRODUÇÃO}

O conceito de nanotecnologia surgiu quando o físico norte-americano Richard Philips Feynman, em sua conferência proferida em 1959 no Instituto de Tecnologia da Califórnia - EUA, propôs que os materiais pudessem ser obtidos e trabalhados em escala atômica. Mais tarde, nos anos de 1980, a construção de microscópicos de alta resolução permitiu que a ciência, especialmente a química, pudesse desenvolver trabalhos na área da nanociência e, já na última década do século passado e a do início deste, diversos progressos foram realizados. Estruturas nesta escala apres entam propriedades funcionais únicas que não são encontradas na escala macro. Neste sentido, nanotecnologias em eletrônica, informática, fármacos, cosméticos, agroquímica, entre outros, vem sendo, desde então, disponibilizados. (SARGENTELLI, 2012; SAHOO, PARVEEN, PANDA, 2007; CHAU, WU, YEN, 2007; MELO, PIMENTA, 2004).

Alguns produtos em nanoescala, porém de origem não biológica, já estão sendo comercializados, tais como dióxido de titânio, ouro, prata e cobre que, adicionados aos plásticos, tintas e outros materiais, melhoraram o seu desempenho. Outros produtos estão próximos da comercialização, como veículos de transportes de drogas no corpo humano e nanotubos de carbono (RASHBA, GAMOTA, 2003).

Dentre os materiais de origem orgânica que vêm sendo amplamente pesquisados podemos citar a quitosana, a celulose e, recentemente, a Spirulina. As nanopartículas de quitosana, estudadas na área farmacêutica, são sistemas carreadores de fármacos. As principais vantagens de se utilizar nanopartículas de quitosana são a sua simplicidade e baixo custo de preparação, não necessitando de calor e solventes orgânicos; são reprodutíveis e estáveis; e aplicáveis a uma grande categoria de substâncias: moléculas pequenas, proteínas e polinucleotídeos (TIYBOONCHAI, 2003).

A celulose vem sendo pesquisada na forma de nanocristais de celulose, também conhecidos como "whiskers", que são domínios cristalinos presentes nas microfibrilas de celulose. Estas nanofibras, embora constituídas por molécula de celulose, apresentam ótimo desempenho como partículas de reforço em matrizes poliméricas (NASCIMENTO et al., 2007).

Recentes pesquisas com bionanopartículas provenientes de matéria seca de Spirulina também serão citadas. Estas possuem potencial como agentes na adsorção de corantes e no possível provimento de uma maior quantidade de nutrientes na forma nanométrica.

O objetivo desta revisão foi abordar as bionanopartículas de maior evidência no campo da nanotecnologia, enfatizando seus processos de obtenção, suas características e aplicações nos diversos campos da ciência e tecnologia.

\section{NANOTECNOLOGIA}

Os termos nanociência e nanotecnologia se referem, respectivamente, ao estudo e às aplicações tecnológicas de objetos e dispositivos que tenham ao menos uma de suas dimensões físicas menores que, ou da ordem de, algumas dezenas de nanômetros (MELO; PIMENTA, 2004). A nanotecnologia abarca uma série de diferentes tecnologias baseadas na manipulação da matéria 
em escala nanométrica. Um nanômetro equivale a um bilionésimo do metro (FOLADORl; INVERNIZZI, 2008).

Os conceitos sobre a matéria em escala nanométrica deram início com o físico americano Richard Feynman, ao fim da década de cinquenta. Feynman discorreu sobre como os cientistas poderiam manipular e controlar átomos individuais e moléculas. Uma década após, o Professor Norio Taniguchi cunhou o termo nanotecnologia, porém, esta área teve seu desenvolvimento efetivo somente a partir de 1981, com a descoberta do microscópio de varre dura por tunelamento (FERREIRA; RANGEL, 2009).

A nanotecnologia possui aspectos que podem contribuir em significativos avanços em diversos setores, como a indústria química, têxtil e automobilística. A matéria em escala nanométrica tem suas propriedades físicas e químicas modificadas. Estas novas propriedades podem ser manipuladas para a fabricação de produtos com múltiplas funções, que possam interagir de maneira inteligente com o meio onde estarão (FOLADORI; INVERNIZZI, 2008).

Considerada a tecnologia-chave do século XXI, a nanotecnologia tem grande potencial de vendas. Através dela será possível produzir medicamentos mais eficazes, materiais mais resistentes, computadores com maior capacidade de armazenamento, além de acarretar benefícios socioambientais (BRASIL, 2010).

\section{QUITOSANA}

Quitosana é um polímero natural, obtido pela desacetilação alcalina da quitina, um biopolímero encontrado em abundância na natureza, presente nos exoesqueletos de diversos crustáceos, na parede celular de fungos (bem como a quitosana) e em outros materiais biológicos. Quitina é o nome usual do composto químico $\beta$-(1-4)-N-acetil-D-glucosamina e é a maior fonte para a obtenção da quitosana. A descoberta da quitosana data do século XIX, porém, somente nas últimas décadas a importância deste polímero tem crescido significativamente em função de ser uma fonte renovável, biodegradável e biocompatível. Há também um recente aumento no conhecimento de sua funcionalidade nas aplicações tecnológicas e biomédicas, além de possuir comprovada atividade antimicrobiana e antifúngica (LARANJEIRA; FÁVERE,2009; MOURA et al.,2006; Ql et al., 2004).

A quitosana é uma poliamina linear, também considerada uma amina catiônica, que possui grupamentos disponíveis para reações químicas, as quais são atribuídas as propriedades de maior interesse. Tais grupamentos podem adquirir uma carga positiva em presença de soluções ácidas, daí sua capacidade de solubilizar-se em ácidos orgânicos, uma das principais diferenças em relação à quitina. A figura 1, adaptada de Battisti e Campana-Filho (2008), mostra a diferença estrutural entre quitina e quitosana, sendo a quitosana composta por unidades $\beta$ - 1,4 D-glucosamina ligadas a resíduos de $\mathrm{N}$-acetilglucosamina (FAl et al, 2008; MOURA et al., 2006). 


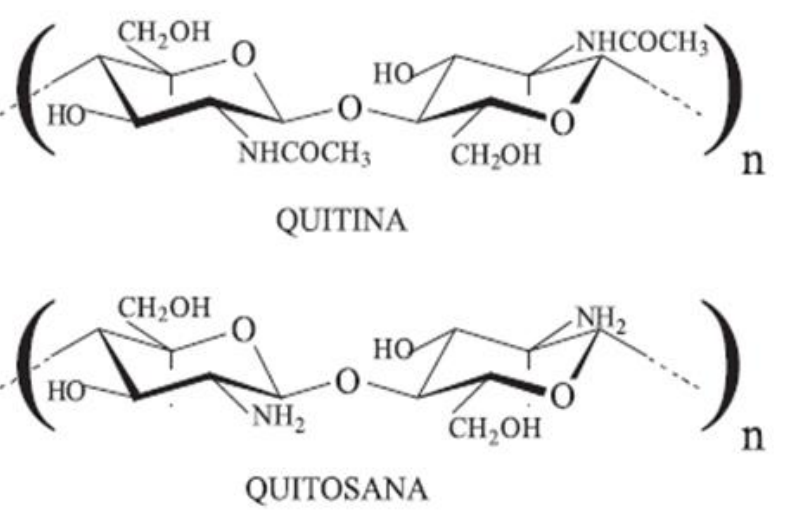

Figura 1 - Representações das estruturas primárias de quitina e quitosana, onde $\mathbf{n}$ é o grau de polimerização.

Dentre as propriedades biológicas da quitosana, a atividade antibacteriana está entre as de maior relevância. Tal propriedade é influenciada por diversos fatores tais como o tipo de quitosana, seu grau de polimerização, $\mathrm{pH}$ da solução e algumas outras propriedades físicoquímicas. Esta propriedade é mais acentuada contra bactérias Gram-positivas (Ql et al., 2004).

Este polímero possui grande potencial industrial biomédico já consagrado, sendo utilizado também em sistemas de liberação de fármacos, engenharia de tecidos, como analgésico e glicosamina no combate à artrite (LARANJEIRA; FÁVERE, 2009, SILVA et al., 2009).

No que tange à legislação vigente no país, a ANVISA regulamenta o uso de quitosana como alimento com alegação de propriedades funcionais e ou de saúde. Sua alegação é de que a quitosana auxilia na redução da absorção de gordura e colesterol e seu consumo deve estar associado a uma alimentação equilibrada e hábitos de vida saudáveis (ANVISA, 2009).

Nanopartículas de quitosana são partículas sólidas coloidais com diâmetros variando entre 1 - $1000 \mathrm{~nm}$. Estas são preparadas a partir de macromoléculas e podem ser utilizadas terapeuticamente como um adjuvante em vacinas e carreadores de substâncias, onde o composto ativo está dissolvido, retido, encapsulado, adsorvido ou quimicamente ligado (TIYABOONCHAl, 2003).

Sistemas coloidais, como lipossomas e nanopartículas, já são bastante investigados na área farmacêutica para o controle da liberação de fármacos em sítios de ação específicos, visando a velocidade de cedência e regime de dosagem de substâncias (SCHAFFAZICK; GUTERRES, 2003). As nanopartículas constituídas de polímeros biodegradáveis têm atraído mais atenção dos pesquisadores em relação aos lipossomas, devido às suas potencialidades terapêuticas, a sua maior estabilidade nos fluidos biológicos e durante o armazenamento (SOPPIMATH et al., 2001).

A quitosana por ser mucoadesiva, promove um prolongamento do contato entre o substrato e a membrana celular, e seu tamanho nanométrico facilita a absorção das substâncias através da membrana. O biopolímero quitosana pode ser modificado fisicamente, sendo esta uma de suas vantagens mais interessantes - a sua grande versatilidade em ser preparado em diferentes formas, tais como pós, flocos, micro-esferas, nanopartículas, membranas, esponjas, colméias, fibras e fibras ocas (LARANJEIRA; FÁVERE, 2009; TIYABOONCHAI, 2003.) sendo de grande importância na indústria farmacêutica e, mais recentemente, na indústria de alimentos e embalagens inteligentes. 
Os métodos de preparação de nanopartículas devem ser estudados cuidadosamente, pois deles resultam as propriedades desejadas. Diferentes técnicas são empregadas de acordo com o polímero utilizado: polimerização, polímeros pré-formados e geleificação iônica, sendo este último, o método mais adequado para polímeros hidrofílicos como quitosana (NAGAVARMA et al., 2012).

O método de geleificação iônica utilizando tripolifosfato de sódio foi des crito por Calvo et al. (1997). Nesta técnica, as cargas positivas dos grupos amino da quitosana interagem com as cargas negativas do poliânion tripolifosfato de sódio e formam coacervados de tamanho nanométrico. Estes coacervados são formados como um resultado das interações eletrostáticas entre as duas fases aquosas, enquanto que geleificação iônica envolve a transição de materiais da forma líquida para a forma de gel (CALVO et al., 1997; NAGAVARMA et al., 2012).

Aplicações de nanopartículas de quitosana estão presentes em diversos campos da ciência. Além da liberação controlada de fármacos, nanopartículas de quitosana tem sido utilizada para regeneração tecidual, particularmente para cartilagens, e em sistemas de imobilização de células em gel (LARANJEIRA; FÁVERE, 2009). Aouada (2009) desenvolveu filmes protetores em alimentos, utilizando nanopartículas de quitosana, as quais apresentaram boa estabilidade, contribuindo para a melhora das propriedades funcionais dos filmes.

Yamamura e colaboradores (2008) incorporaram nanopartículas de magnetita à nanopartículas de quitosana, conferindo a estas propriedades magnéticas que poderão auxiliarnos processos de tratamento de águas residuárias.

Blanco (2011) inseriu nanopartículas de quitosana ao cimento endodôntico AH PLUSTM, verificando que suas propriedades não são alteradas, sendo esta técnica de grande potencial no tratamento endodôntico, porém, necessitando de avanços nesses estudos.

\section{CELULOSE}

A celulose é o componente orgânico mais abundante na Terra, sendo um polissacarídeo de fórmula geral $\left(\mathrm{C}_{6} \mathrm{H}_{10} \mathrm{O}_{5}\right)_{n}$. A unidade repetitiva desse polímero é composta por duas unidades de glicose unidas por ligação $\beta$-1,4-glicosídicas, conhecidas como celobiose, que contém seis grupamentos hidroxila, estabelecendo assim, ligações de hidrogênio intra e intermoleculares. Devido à estas ligações, a celulose possui uma tendência a formar cristais insolúveis em água e na maioria dos solventes orgânicos (CORRÊA, 2010).

Nanofibras de celulose são encontradas nas paredes celulares secundárias, na forma de fibras, filmes, entre outros (BHATNAGAR; SAIN, 2005). Para a obtenção de nanofibras de celulose, basicamente são utilizados três processos diferentes: métodos químicos, métodos mecânicos e métodos enzimáticos, sendo o processo de hidrólise ácida o mais recomendado (LUNZ; COUTINHO; SIMÃO, 2012). Essas nanofibras, quando isoladas, têm sido avaliadas como material de reforço em matrizes poliméricas pelo seu potencial em melhorar as propriedades mecânicas, ópticas, dielétricas, dentre outras, dessas matrizes. As nanofibras de celulose possuem inúmeras vantagens em relação a outros materiais nanoestruturados como, por exemplo, a facilidade no processo de formação, o baixo custo da matéria prima, as características diversificadas em função do subs trato natural de origem e, ainda, as propriedades mecânicas comparáveis com as de nanotubos de carbono e de nanofibras inorgânicas (NOORANI; SIMONSEN; ATRE; 2007). 
A utilização de fibras naturais, como nanofibras de celulose, em compósitos poliméricos tem recebido grande volume de pesquisas na diligência de desenvolvimento de materiais biodegradáveis e de alto desempenho mecânico (MAAFI et al., 2010). A Tabela 1 resume os termos utilizados para descrever a nanocelulose, bem como as diferentes origens da cel ulose, os métodos de produção mais utilizados e tamanhos médios obtidos.

Tabela 1 -Celulose: Termos, processos, origens e dimensões

\begin{tabular}{|c|c|c|c|c|}
\hline Tipos de celulose & Sinônimos & Processos & Origem & Dimensões \\
\hline $\begin{array}{c}\text { Celulose } \\
\text { nanofibrilada }\end{array}$ & $\begin{array}{c}\text {-Celulose } \\
\text { microfibrilada } \\
\text {-Nanofibrilas } \\
\text {-Microfibrilas }\end{array}$ & $\begin{array}{c}\text { - Pré tratamento químico } \\
\text { seguido de tratamento } \\
\text { mecânico }\end{array}$ & $\begin{array}{l}\text {-Cânhamo } \\
\text {-Linho } \\
\text {-Batata }\end{array}$ & $\begin{array}{c}\text {-Diâmetro: } 5 \text { a } 60 \mathrm{~nm} \\
\text {-Comprimento: Até vários } \\
\mu \mathrm{m}\end{array}$ \\
\hline \multirow[t]{2}{*}{$\begin{array}{l}\text { Nanowhiskers de } \\
\text { celulose }\end{array}$} & $\begin{array}{l}\text {-Nanocristais } \\
\text {-Microcristais }\end{array}$ & -Hidrólise ácida & $\begin{array}{l}\text {-Linho } \\
\text {-Algodão }\end{array}$ & $\begin{array}{l}\text {-Diâmetro: } 2 \text { a } 20 \mathrm{~nm} \\
\text {-Comprimento: } 50 \text { a } 600 \mathrm{~nm}\end{array}$ \\
\hline & -Whiskers & $\begin{array}{l}\text {-Processo biológico de } \\
\text { tunicados }\end{array}$ & $\begin{array}{l}\text {-Celulose } \\
\text { tunicada }\end{array}$ & $\begin{array}{c}\text { Comprimento: } 100 \mathrm{~nm} \text { à } \\
\text { vários } \mu \mathrm{m}\end{array}$ \\
\hline $\begin{array}{l}\text { Nanocelulose } \\
\text { bacteriana }\end{array}$ & $\begin{array}{c}\text {-Celulose } \\
\text { bacteriana } \\
\text {-Biocelulose }\end{array}$ & -Síntese bacteriana & $\begin{array}{l}\text {-Álcoois } \\
\text {-Açucares }\end{array}$ & Diâmetro: 20 a $100 \mathrm{~nm}$ \\
\hline
\end{tabular}

Fonte: Adaptado de NUNES, 2014

Fujimoto (2011) produziu um nanocompósito contendo poli -3-hidroxibutirato e nanopartículas de celulose e amido provenientes de subprodutos da indústria amilácea. Os resultados foram satisfatórios, mostrando que uma concentração de nanopartículas de até $0,10 \%$ permite um aumento da temperatura na qual o material pode ser processado. $O$ interesse por nanomateriais não se deve apenas à melhoria das propriedades de desempenho de matrizes, mas também vislumbra o desenvolvimento de novos produtos utilizando-os como material de reforço (SILVA et al., 2009).

\section{SPIRULINA}

A cianobactéria Spirulina (Arthrospira platensis) é um micro-organismo aquático, de cor verde azulada, que possui um filamento helicoidal multicelular. A Spirulina possui envoltório celular mais parecido com uma bactéria do que com uma alga, isto é, suas paredes celulares são mais digeríveis uma vez que são formadas por mucopolissacarídeos e não por celulose, o que representa vantagem do ponto de vista de preservação da integridade de seus componentes, como vitaminas e ácidos graxos poliinsaturados (TOMASELLI, GIOVANNETTI, TORZILLO, 1993).

Com relação a seu aspecto como alimento, a Spirulina é bastante atrativa, pois esta apresenta teores de proteína mais elevados que a carne de peixes (15-25\%), que sementes de soja (35\%), ovos (12\%), cereais (8-14\%) e leite integral (3\%). Quanto aos aminoácidos, na Spirulina os limitantes são a cisteína e a metionina, porém apresentam-se nesta alga em quantidades superiores às encontradas em cereais, sementes e verduras (HENRIKSON,1994). A Spirulina, em maio de 2009, passou a fazer parte da Lista de Novos Ingredientes (enquadrada nos Alimentos com Alegações de Propriedades Funcionais e/ou de Saúde, Novos Alimentos/Ingredientes, Substâncias Bioativas e Probióticos) aprovada pela Agência Nacional de Vigilância Sanitária, a qual limita a sua ingestão diária em 1,6g por indivíduo (ANVISA, 2009). 
As pesquisas com relação à nanopartículas de Spirulina são recentes e muito res tritas. Dotto e Pinto (2012) descreveram a metodologia para a preparação de nanopartículas derivadas desta alga, com o objetivo de estudar o potencial que nanopartículas desta origem têm de remover corantes de soluções aquosas. Estes autores estudaram a bioadsorção de corantes de efluentes industriais por micro e nanopartículas da cepa LEB-18. Foi verificado que o tamanho médio das partículas influencia na quantidade de corante bioadsorvido, tendo as nanopartículas de Spirulina uma maior capacidade de retenção deste corante, apesar da menor cinética de adsorção quando comparadas às micropartículas (DOTTO, CADAVAL, PINTO, 2012).

Machado (2012), em seus estudos, investigou as propriedades biológicas e nutricionais da Spirulina LEB-18 em suas formas micro e manométricas. Ratas wistar foram submetidas à dietas à base de Spirulina micro e manométricas. Foi verificado que as dietas não diferiram significantemente em parâmetros biológicos como o índice de glicemia e minerais no soro.

Mahdieh e colaboradores (2012) estudaram a produção de nanopartículas de prata por Spirulina platensis, cepa PCC 9108. Nanopartículas de prata já são reconhecidas pelo seu poder cicatrizante e antimicrobiano, porém, seus métodos de preparo envolvem reagentes tóxicos. A produção de nanopartículas por Spirulina platensis e por outros microrganismos é chamada de "síntese verde" e possui as vantagens de ser biológico, renovável e de baixo custo. Mahdieh e colaboradores concluíram que a biomassa desta microalga é efetiva na produção de nanopartículas de prata, indicando o potencial futuro desta microalga em produzir outros nanocompostos no campo da bionanotecnologia.

\section{CONSIDERAÇÕES FINAIS}

A nanotecnologia vem sendo desenvolvida e elucidada nas últimas décadas, e tem se mostrado como tecnologia promissora e revolucionária, por permitir que a matéria adquira novas propriedades físicas. É visto que na engenharia de materiais, na química e no campo farmacêutico esta nova ciência já tem seu campo consolidado e continua expandindo, porém, se faz necessário mais pesquisas em outros campos de aplicação, como na indústria de alimentos. $O$ desenvolvimento de nanobiopartículas de caráter biocompatível, provindas de fontes renováveis e que não agridem o meio ambiente poderá otimizar os processos de produção, melhorar as condições de armazenamento bem como agregar valor em diversos produtos, principalmente daqueles para consumo humano.

\section{REFERÊNCIAS}

1. ANVISA, (2009) - AGÊNCIA NACIONAL DE VIGILÂNCIA SANITÁRIA. Novos alimentos aprovados. Disponível em: <http://portal.anvisa.gov.br>. Acesso em: abril de 2014.

2. AOUADA, M.R.M. Aplicação de nanopartículas em filmes utilizados em embalagens para alimentos. Tese (Doutorado) - Programa de Pós-graduação em Química. Universidade Federal de São Carlos, São Carlos, 2009.

3. BATTISTI, M. V.; CAMPANA-FILHO, S.P. Obtenção e caracterização de $\alpha$-quitina e quitosanas de cascas de Macrobrachium rosembergii. Química Nova, v. 31, n. 8, p. $2014-2019,2008$.

4. BHATNAGAR, A.; SAIN, M. Processing of Cellulose Nanofiber-reinforced Composites. Journal 
of Reinforced Plastics and Composites, v. 24, p.1259-1268, 2005.

5. BLANCO, M.A. Avaliação da incorporação de nanopartículas de quitosana ao cimento endodôntico AH PLUS. Dissertação (Mestrado) - Programa de Pós-Graduação em Odontologia. Universidade Federal do Rio de Janeiro, Rio de Janeiro, 2011.

6. BRASIL, (2010) - Tecnologia de ponta: Nanotecnologia. Disponível em: <http://www.brasil. gov.br/ciencia-e-tecnologia/2010/08/nanotecnologia> Acesso em: abril de 2013.

7. CALVO, P.; REMUNÃN-LÓPEZ, C.; VILA-JATO, J. L.; ALONSO, M. J. Development of positively charged colloidal drug carriers: Chitosan coated polyester nanocapsules and submicronemulsions. Colloid and Polymer Science, v. 275, n. 1, p. $46-53,1997$.

8. CHAU, C. F.; WU, S. H.; YEN, G. C.; The development of regulations for food nanotechnology. Trends in Food Science \& Technology, n.18, p. $269-280,2007$.

9. CORRÊA, A.C. Preparação de nanofibras de celulose a partir de fibras de curauá para desenvolvimento de nanocompósitos poliméricos com eva. Tese (Doutorado) - Programa de Pós-Graduação em Engenharia e Ciência de Materiais. Universidade Federal de São Carlos, São Carlos, 2010.

10. DOTTO, G. L.; CADAVAL, T. R. S.; PINTO, L. A. A. Use of Spirulina platensis micro and nanoparticles for the removal synthetic dyes from aqueous solutions by biosorption. Process Biochemistry, n.47, p. $1335-1343,2012$.

11. FAI, A. E. C.; STAMFORD, T. C. M.; STAMFORD, T. L. M. Potencial biotecnológico de quitosana em sistemas de conservação de alimentos. Revista Íberoamericana de Polímeros, v. 9, n. 5, p. $435-451,2008$.

12. FERREIRA, H.D.; RANGEL, M.C. Nanotecnologia: Aspectos gerais e potencial aplicação em catálise. Quimica Nova, v. 32, n. 7, p.1860-1870, 2009.

13. FOLADORI, G.; INVERNIZZI, N. Nanotecnologías en la Alimentación y Agricultura. Montevideo: Universidad de la República, 2008. 116 p.

14. FUJIMOTO, D.Y.; Produção de nanocompósitos poli(3-hidroxibutirato) / nanopartículas obtidas a partir de subprodutos da indústria amilácea. Projeto de Graduação. Universidade Federal do Rio de Janeiro, Rio de Janeiro, 2011.

15. HENRIKSON, R. Microalga Spirulina - Superalimento del futuro. Barcelona: Ediciones S.A. Urano, ISBN 84-7953-047-2.

16. LARANJEIRA, M. C. M.; FÁVERE, V. T. Quitosana: Biopolímero funcional com potencial industrial biomédico. Química Nova, v. 32, n. 3, p. 672 - 678, 2009.

17. LUNZ, J. N.; COUTINHO, P. R.; SIMÃO, R.A. Revisão dos métodos de obtenção de nanofibra de celulose e compatibilização por plasma. Anais do Congresso Painel PEMM PEMM/COPPE/UFRJ, Rio de Janeiro, RJ, Brasil, 2012.

18. MAAFI, E. M.; MALEK, F.; TIGHZERT, L.; DONNY, P. Synthesis of polyurethane and characterization of its composites based on alfa cellulose fibers. Journal of Polymers and the Environment, v. 18, n.4, p. $638-646,2010$.

19. MACHADO, A. R. Avaliação biológica da Spirulina em tamanho micro e manométrico e estudo da sua encapsulação em lipossomas. Dissertação (Mestrado) - Programa de Pós-Graduação em Engenharia e Ciência de Alimentos - Universidade Federal do Rio Grande, Rio Grande, 
2012.

20. MAHDIEH, M.; ZOLANVARI, A.; AZIMEE, A. S.; MAHDIEH, M. Green biosyntesis of silver nanoparticles by Spirulina platensis. Sharif University of Technology, v.19, n.3, p. $926-929$, 2012.

21. MELO, C. P.; PIMENTA, M. Nanociências e Nanotecnologias. Parcerias Estratégicas, n. 18, p.922, 2004.

22. MOURA, C.; MUSZINSKI, P.; SCHMIDT, C.; ALMEIDA, J.; PINTO, L. Quitina e quitosana produzidas a partir de resíduos de camarão e siri: Avaliação do processo em escala piloto. Vetor, v. 16, p. $37-45,2006$.

23. NAGAVARMA, B. V. N.; HEMANT, K. S. Y.; AYAZ, A.; VASUDHA, L. S.; SHIVAKUMAR, H. G. Different techniques for preparation of polymeric nanoparticles - A review. Asian Journal of Pharmaceutical and Clinical Research, v. 5, n. 3, p. $16-23,2012$.

24. NASCIMENTO, D.M.; ROSA, M.F.; NORÕES, A.K.; FILHO, M.S.M.S.; BRITO, M.C.; MORAIS, J.P.S. Nanopartículas de celulose obtidas de resíduos industriais. In: ENCONTRO DE INICIAÇÃO CIENTÍFICA DA EMBRAPA AGROINDÚSTRIA TROPICAL, 2010, Fortaleza. Resumos de Anais. Fortaleza: Embrapa Agroindústria Tropical, 2007.

25. NOORANI, S.; SIMONSEN, J.; ATRE, S. Nano-enable microtechnology: polysulfone nanocomposites incorporanting celulose nanocrystals. Cellulose, n.14, p. $577-584,2007$.

26. NUNES, T. F. P. Produção, caracterização e aplicação de nanofibras de celulose. Dissertação (Mestrado) - Programa de Pós-Graduação em Engenharia Química, Universidade de Coimbra, Coimbra, Portugal, 2014.

27. QI, L.; ZIRONG, X.; JIANG, X.; CAIHONG, H.; ZOU, X. Preparation and antibacterial activity of chitosan nanoparticles. Carbohydrate Research, v. 339, p. $2693-2700,2004$.

28. RASHBA, E.; GAMOTA, D. Anticipatory standards and the commercialization of nanotechnology. Journal of Nanoparticle Research, n. 5, p. 401-407, 2003.

29. SAHOO, S. K.; PARVEEN, S.; PANDA, J. J.; The present and the future of nanotechnology in human health care. Nanomedicine: Nanotechonology, Biology, and Medicine, v.3, p. 20-31, 2007.

30. SARGENTELLI, V.; Nanociência: Aplicações tecnológicas em química, saúde, agricultura e meio ambiente: uma sinopse. Revista Eletrônica Ambiente Gestão \& Desenvolvimento, v.4, n.1, 2012.

31. SCHAFFAZICK, S. R.; GUTERRES, S. S.; Caracterização e estabilidade físico-química de sistemas poliméricos nanoparticulados para administração de fármacos. Química Nova, v. 26, n. 5, p. $726-737,2003$.

32. SILVA, R.; HARAGUCHI, S.K.; MUNIZ, E.C.; RUBIRA, A.F. Aplicações de fibras lignocelulósicas na química de polímeros e em compósitos. Química Nova, v. 32, n. 3, p. 661-671, 2009.

33. SOPPIMATH, K. S.; AMINABHAVI, T. M.; KULKARNI, A. R.; RUDZINSKI, W. E. Biodegradable polymeric nanoparticles as drug delivery devices. Journal of Controlled Release, v. 70, p. 1 20, 2001.

34. TIYABOONCHAl, W. Chitosan nanoparticles: A promising system for drug delivery. Naresuan University Journal, v. 11, n. 3, p. $51-66,2003$. 
35. TOMASELLI, L., GIOVANNETTI, L., TORZILLO, G. Physiology of stress response in Spirulina spp. In: DOUMENGE, F.; DURAND- CHASTEL, H. \& TOULEMONT, A. (eds). Spiruline Algue de Vie. Bulletin de L'Institut Océanographique, Monaco, n.12, p.65-75, 1993.

36. YAMAMURA, M.; HORITA, A.S.; ODA, H.T.Y.; STOPA, L.C.B. Caracterização das partículas magnéticas de quitosana. 180 CBECiMat - Congresso Brasileiro de Engenharia e Ciência dos Materiais, 24 a 28 de Novembro de 2008, Porto de Galinhas, PE, Brasil. 